\title{
Necessary But Not Sufficient: Literacy Pedagogies for Changing Times
}

\author{
JOANNE O'MARA \\ Deakin University \\ GLENN AULD \\ Deakin University \\ NARELLE WOOD \\ Deakin University
}

\begin{abstract}
This paper argues the case for expansive and inclusive models of literacy pedagogy that can be applied to curricula more generally. Literacy pedagogy in Australia has benefited from using Freebody and Luke's (1990) Four Roles of the Reader model. We analyse the Paul Kelly song video, Sleep, My Country, Sleep, using this model. Unpinning this model is the concept that each role is necessary but not sufficient. We discuss the benefits of pluralism in language and literacy pedagogy in an age of standards-based reforms and shifting repertoires of literacy practices in pedagogies that speak back to the Anthropocene.
\end{abstract}

Keywords

Anthropocene, literacy pedagogy, four roles of the reader

\section{Introduction}

As settler Australians we acknowledge that this paper was written on Wurundjeri and Boon Wurrung Country in Melbourne, Australia. We acknowledge we are on unceded Aboriginal lands. We acknowledge the Elders - past, present and emerging of all the land we work and live on and their Ancestral Spirits with gratitude and respect.

In this paper we focus on the influence of Freebody and Luke's (1990) Four Roles of the Reader model, and how this model has enabled Australian teachers, school leaders, academics and policy writers to work successfully with young people and to innovate in their practice. In Australia the subject "Language Arts" is always referred to as "English", and almost always conducted in English.

We also want to acknowledge the work of Luke and Freebody who coined the term "necessary but not sufficient" in literacy pedagogy in Australia in 1990, and the contribution that they have made, individually, and together, to our own and our country's understandings of literacy. In reflecting on the four resources model in 1999 they wrote:

The key concept in the model is, necessity and not sufficiency - each one is necessary for literacy in new conditions, but in and of themselves, none of the four families of practice is sufficient for literate citizens/ subjects (p. 7).

At that time there was a divisive approach towards literacy pedagogy in Australia, where practitioners and theorists were positioned in different camps-phonics, whole language, genre, and critical literacy. Also at the time, many teachers believed you should 
only work with students' texts, while others had strong beliefs that students should rote learn spelling words and know all the rules of grammar. Genre theorists, such as Christie and Derewianka (2008) were promoting the study of the structures of texts and associated rules. These fracture lines split the language and literacy teaching community-from university lecturers and courses, through subject associations and teachers. The learning in the classroom was far from uniform and learning experience depended on the teacher's individual beliefs and practices towards literacy.

It was in this environment that Luke and Freebody designed the Four Roles of the Reader, a framework for understanding the repertoires of literacy practices. This model is inclusive of the many theoretical and practical positions held about literacy. There are stories circulating the language and literacy community that Allan and Peter met over coffee and mapped out the model on the back of a napkin. Freebody (2007) described that: Its original aim was to provide an accessible and inclusive framework for discussions of literacy education, while at the same time affording a range of pedagogical strategies and frameworks for teaching literacy and for understanding various disciplines' orientations to literacy education (p. 35).

In this paper we argue that the original intentions of this model have served Australia well, and that the framework has shaped the understandings of literacy nationally. We use the repertoire of practices outlined in the model to illustrate opportunities for the teaching of language and literacy teaching when reading multi-model texts. We begin with a literature review that traces the ways in which the four resources model has been used in Australia to underpin literacy teaching in schools and in the Australian Curriculum, as it has been applied across early childhood, primary and secondary contexts. We also explore how the model enables practitioners and policy makers to critique reductive approaches to literacy pedagogy. We then analyse the Paul Kelly song video, Sleep, My Country, Sleep, using the Four Roles of the Reader. We have produced a series of questions for understanding the different ways of reading this text, highlighting how each approach is necessary but not sufficient. We conclude with a discussion of the benefits of pluralism in language and literacy pedagogy in an age of standards-based reforms and shifting repertoires of literacy practices.

\section{Literature Review}

Through a historical analysis, Luke \& Freebody (1999) argue that literacy refers to a 'malleable set of cultural practices that are shaped and reshaped by different, often competing social and cultural interests' (p. 5). These two authors proposed a model that outlined four roles of literacy that people use to develop and maintain an understanding of texts (Freebody \& Luke, 1990). These roles are outlined below in Table 1. 
Table 1

Four Roles of the Reader from Freebody (2007)

\begin{tabular}{|c|c|c|}
\hline Role's Name & Focus & Examples \\
\hline Code-breaker & $\begin{array}{l}\text { Knowing about and using the } \\
\text { nature and contents of the } \\
\text { relationship of spoken sounds } \\
\text { in the language to the graphic } \\
\text { symbols used to represent } \\
\text { those sounds, and basic } \\
\text { visual aspects of textual } \\
\text { formatting }\end{array}$ & $\begin{array}{l}\text { Sound-letter } \\
\text { correspondences, phonemes } \\
\text { relevant to English, } \\
\text { punctuation, decoding the } \\
\text { elements and structural } \\
\text { compositions of pictures and } \\
\text { graphic displays, hotlinks on } \\
\text { web pages }\end{array}$ \\
\hline Text-participant & $\begin{array}{l}\text { Knowing about and using } \\
\text { the meaning patterns } \\
\text { operating in the written } \\
\text { texts, participating in the } \\
\text { ongoing construction of the } \\
\text { text's meaning as a } \\
\text { collection of propositions }\end{array}$ & $\begin{array}{l}\text { Participating in the stated } \\
\text { and unstated patterns of } \\
\text { information that hold the } \\
\text { text together, including } \\
\text { vocabulary } \\
\text { knowledge, and capitalising } \\
\text { on syntactic knowledge to } \\
\text { build a representation of the } \\
\text { significance and implications } \\
\text { of a text }\end{array}$ \\
\hline Test-user & $\begin{array}{l}\text { Knowing about and using } \\
\text { the social and cultural } \\
\text { functions of various kinds of } \\
\text { reading and writing practices, } \\
\text { building into a repertoire of } \\
\text { purposeful and effective } \\
\text { communications }\end{array}$ & $\begin{array}{l}\text { The form-function } \\
\text { relationships of various } \\
\text { genres and the } \\
\text { sociocultural, positional } \\
\text { expectations associated } \\
\text { with different kinds of } \\
\text { written and visual } \\
\text { communications }\end{array}$ \\
\hline Text-analyst & $\begin{array}{l}\text { Knowing about and using } \\
\text { the cultural and } \\
\text { ideological bases on which } \\
\text { texts are written and put to } \\
\text { use to mobilise opinion } \\
\text { and standardise } \\
\text { interpretation }\end{array}$ & $\begin{array}{l}\text { How texts differentially } \\
\text { position readers, and how } \\
\text { they use various } \\
\text { sociocultural categories, } \\
\text { evident in linguistic and } \\
\text { visual media, to constrain } \\
\text { interpretation and influence } \\
\text { the reader }\end{array}$ \\
\hline
\end{tabular}

Each of the four roles are necessary, but not sufficient, sets of social practices for literate participation in semiotic economies and cultures (Luke, 2000, p. 456). The roles have been proposed as repertoires of literate practices that allude to the "depth and degree of control exercised by an individual or community in any given literate activity" (Luke \& Freebody, 1999, p. 7 ). Before, during and after the model was conceived, teachers have 
always been working in a space where they have been negotiating their own literacy pedagogies in a context where departments of education were mandating particular approaches and accountabilities. The role of teacher agency and institutional structures are each necessary but not sufficient in literacy pedagogy.

The model is used by teachers to shape the work in Australian classrooms across early childhood, primary and secondary contexts. It is taught extensively in Australian teacher education and features in many textbooks used in pre-service teacher education programs (Fellowes \& Oakley, 2019; Sawyer, 2019; Winch, Johnson, March, Ljungdahl, $\&$ Holliday, 2020). This usage of the model continues through to curriculum documents and support materials for teachers, including references and examples in an online education toolkit (Department of Education and Training, Victoria). The model has had a wide range of applications in middle years contexts from the analysis of fake news with students (Clary \& Bannister-Tyrrell, 2018) to extending student understandings of reading digital texts (Healey, 2016). Extensions of the model developed to cover the reading and viewing of digital texts explore the social practices associated with roles of (1) navigator, (2) interpreter, (3) designer and (4) interrogator (Serafini, 2012).

\section{Sleep, Australia, Sleep: Utilising the Repertoire of Practices.}

In this section of the paper, we invite you to engage with the 2020 song video composed by Australian singer songwriter, Paul Kelly, Sleep, Australia, Sleep. The song video was published on February 6 2020, at the end of an Australian summer when fires had been raging across the country-much earlier than usual and they continued burning through the new year. All of Australia lived through some of the impacts of this-the smoke, bearing witness to some of the devastation that occurred, or more personal and deeper impacts of the loss of lives. The bushfires merged into our experiences of COVID 19 - the extended shutdowns, the community focus on the spread of the virus, and rising death tolls. The two events and the feeling of dystopia they evoked represent a lived experience of the Anthropocene, where the results of decades of human inattention to and exploitation of the environment were having a visible daily impact on our lives.

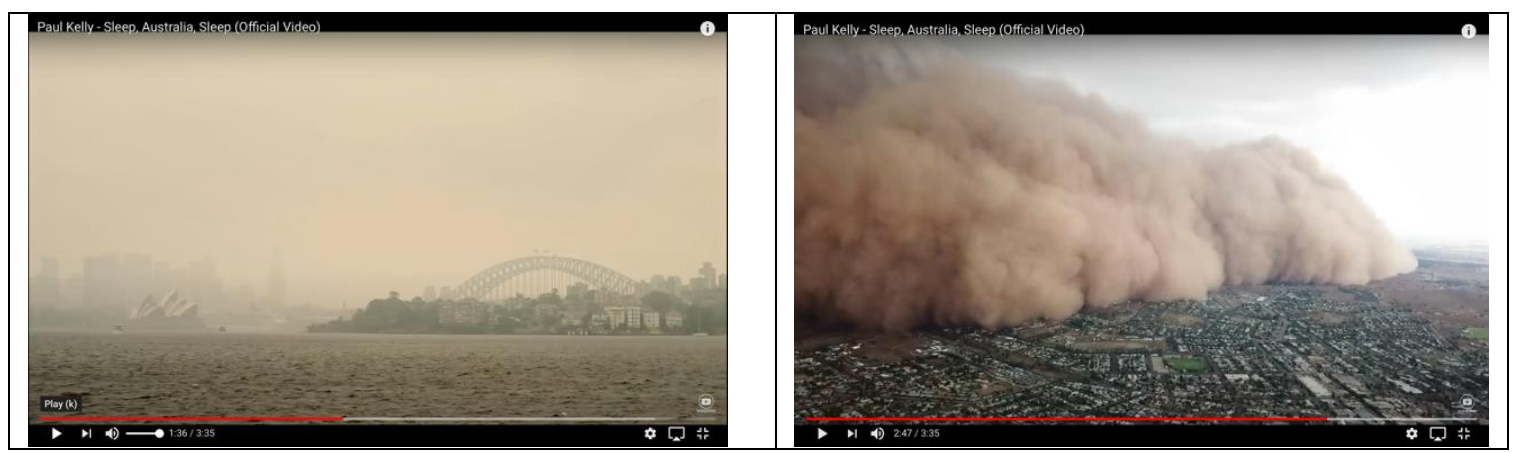



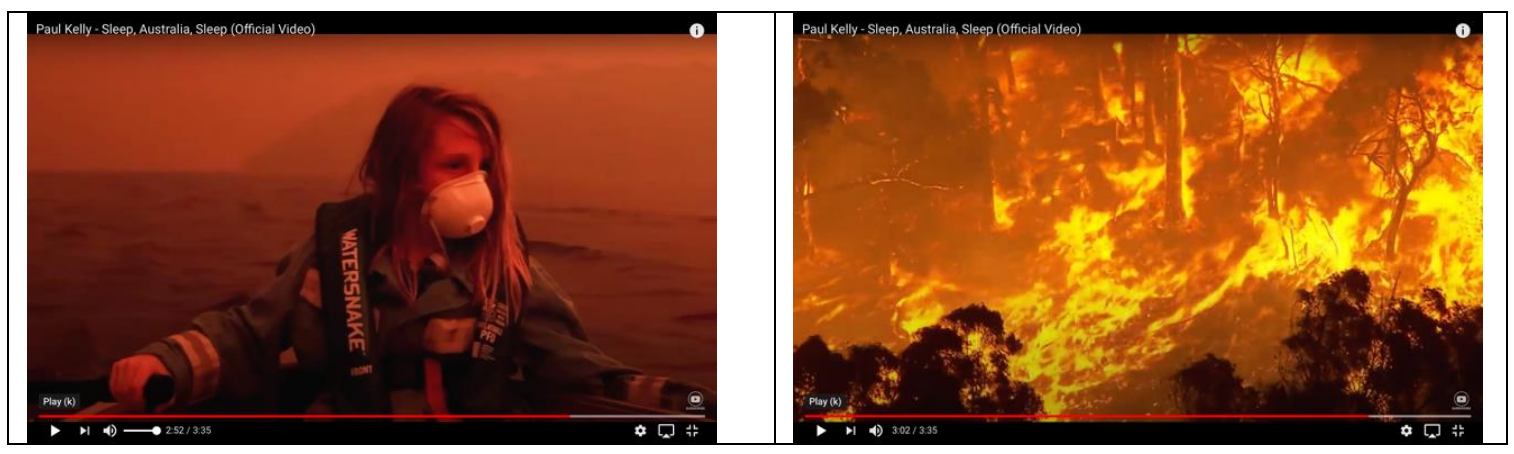

Figure 1. Images of the 2020 Australian Bushfires Used in Sleep, Australia, Sleep

Through the following discussion we lead you through an analysis of this music video where we have used the Four Roles of the Reader model to design our questions for analysing the text. We originally developed this as a workshop which we used with preservice teachers in both a literacy unit for Early Childhood, Elementary and Secondary teachers as well as in the Secondary English specialisation unit. This workshop was designed to enable us to introduce the Four Roles of the Reader model while engaging with a contemporary text that speaks to 2020. The song video brought the issues of the Anthropocene into focus for analysis. We are Paul Kelly fans - he is a legendary Australian singer songwriter - and Sleep, Australia, Sleep is a suitable text to work with for children and young people of all ages. All our pre-service teachers can use this text in their settings and develop curriculum work from what we did in class. We have included the questions we developed for the workshop as Appendix B in this paper. As the music video is freely available online, it would be easy to begin with these questions as a curriculum unit in Elementary or Secondary Language Arts, or it could be used as a way of demonstrating the Four Roles of the Reader model to pre-service teachers. Because the video is focused on Australia, but points to issues that relate to Canada and elsewhere, there is an inbuilt distancing in the focus that can be enabling of difficult conversations for those outside Australia. In the analysis we include in this paper, we demonstrate how each practice contributes to a deeper and more complete reading of the text. As we explore the text following paths shaped by the model, we illustrate how we concurrently utilise multiple practices when we read and view texts. Each of the four roles is necessary, but not sufficient.

In the next section of the paper, we lead you through the analysis of the song video demonstrating the connections and language you might use in a classroom situation when using the four resources model. We write in an inclusive way and address readers, listeners and viewers as "we".

\section{Examining the Multimodal Text of Sleep, Australia, Sleep}

Before you continue reading this paper, we invite you to listen to and watch Sleep, Australia, Sleep. The lyrics are in Appendix A if you would like to refer to them. This YouTube clip is the official song release-Paul Kelly and his team have enabled wide and free distribution. In composing this artwork, Kelly is responding to the Australian summer of 2020 and describes the piece as both a "lament, in the form of a lullaby" and "a critique 
of the widespread attitude among humans that we are the most important life form on the planet". He stated that he believed we have "reached a tipping point where this attitude is doing terrible harm to all life on earth. I hope the song doesn't come true but some of it already has" (Martyn, 2020). We invite you to keep this in mind as you listen to the song and watch the video (it runs for 3.35).

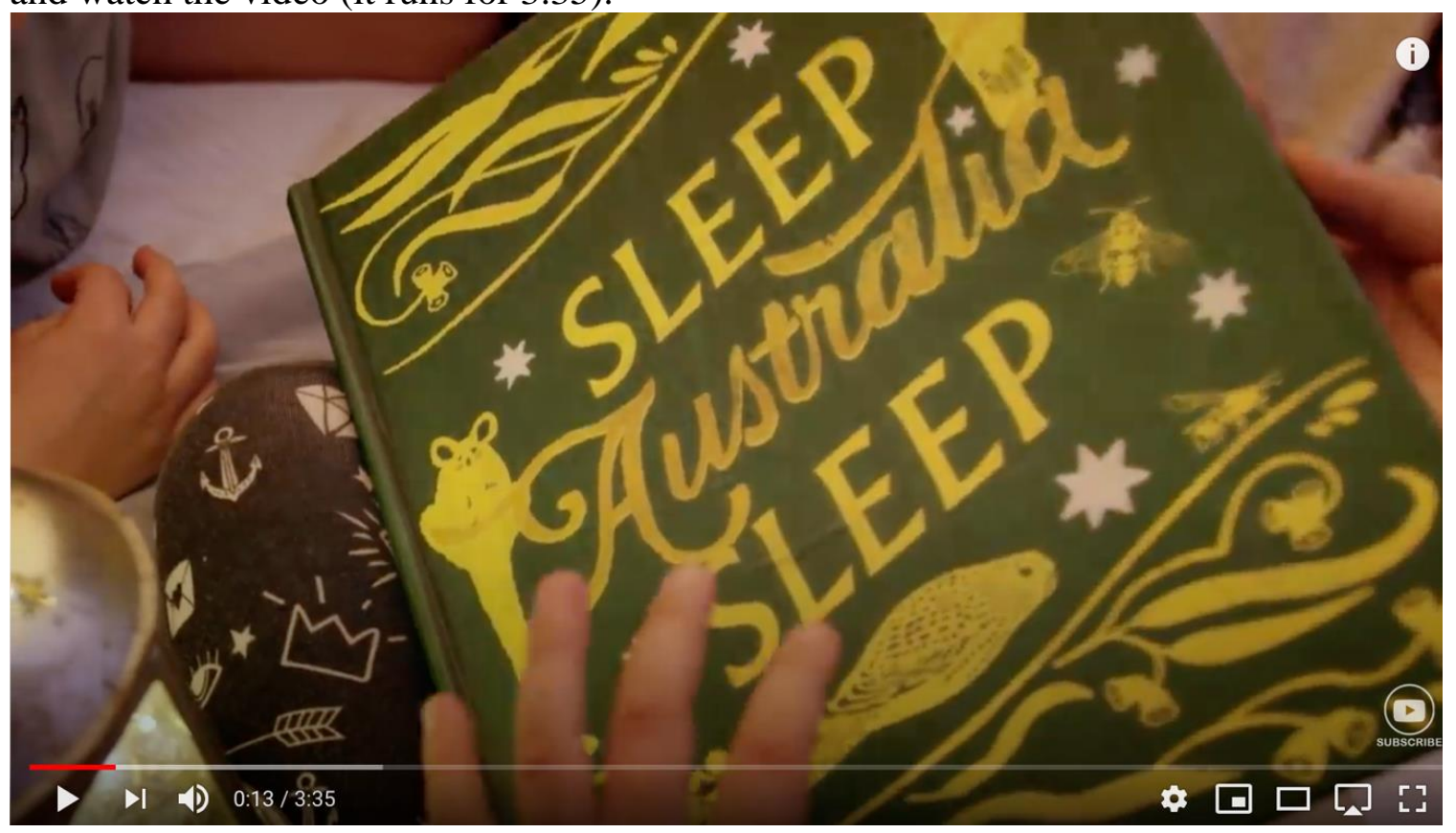

Figure 2. Bedtime Story Book Opening of Sleep, Australia, Sleep.

In our analysis, we follow one journey through this complex, beautiful text and consider how we draw upon our repertoires of reading practices in engaging with the text, and how the practices interweave. The video has a loose overarching narrative where four children go into a tent and listen to this harrowing bedtime story. The top row of images are screenshots from before the bedtime story, the bottom row from afterwards. This is not a bedtime story designed to induce sleep.

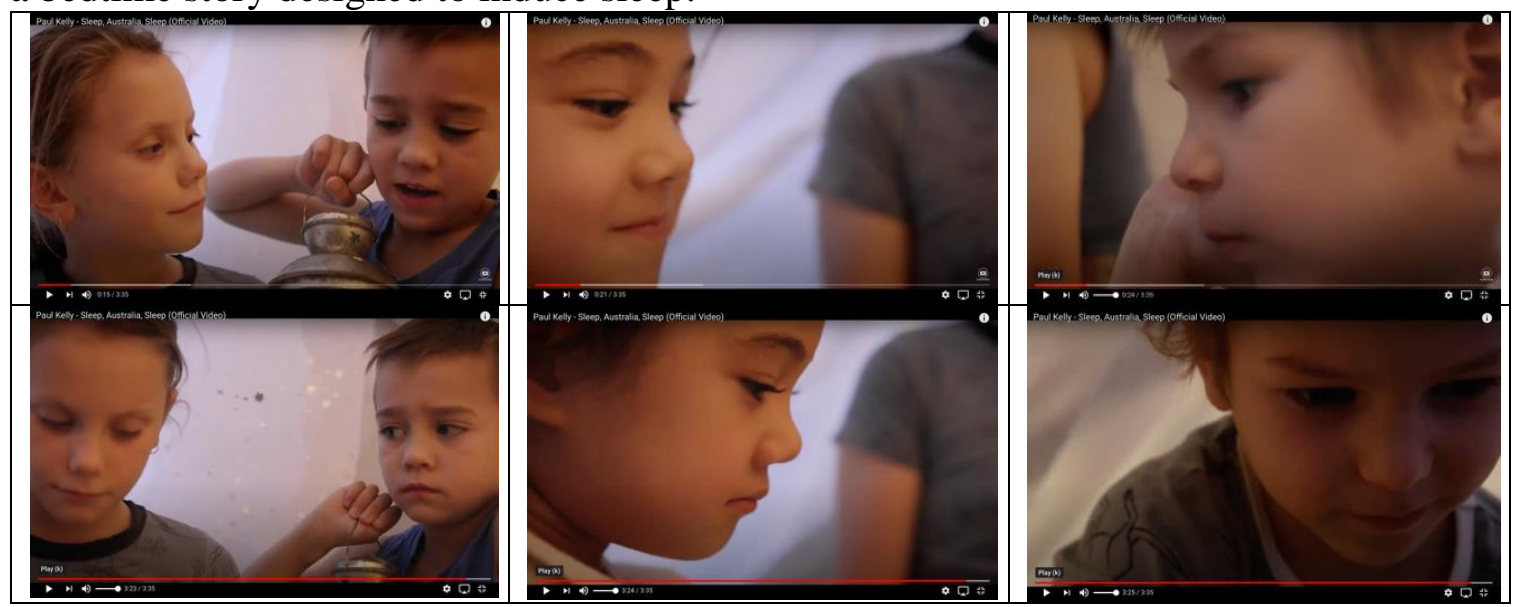

Figure 3. Images of the Children Before and After the Bedtime Story 
We begin with the text code-breaker practice, thinking about the word, "sleep". Sleep is a high frequency word in the text. In working through the model we are cognisant that it is not a hierarchical set of practices. The word is decoded using knowledge of blends $(\mathrm{sl})$ and representations of the vowel sound (ee) in the word. There is an onset (sl) and a rime (eep). The word is represented by five graphemes (a letter or sequence of letters to represent the sounds) and four phonemes (sounds) 's' ' 1 ' 'ee' ' $\mathrm{p}$ '. The reader of this word does not need to know the terms we have used, but may follow the same processes. As beginning readers become familiar with a word, it becomes a sight word, known without consciously decoding the parts of the word. As we hear Kelly sing the word throughout the song, the repetition holds the song together, and he layers multiple meanings on the word as the song progresses.

We move to the text participant role exploring at the ongoing way the meaning of the word "sleep" is negotiated in the text. We look up the word "sleep" in the MerriamWebster online dictionary and begin listing the multiple definitions of the word sleep and looking for these in the video, noting the euphemism of "death" being called "sleep", the temporary loss of feeling in your toes, and the state of hibernating animals. We note the definition that sleep is an "easily reversible periodic state of many living things that is marked by the absence of wakefulness and by the loss of consciousness of one's surroundings..." (Merriam-Webster 2020). By contrast the visuals in the song up to this point provide the viewer with a consciousness around human and non-human interactions.

Kelly uses the idea of counting sheep to get to sleep to drift us into thinking about all the species under threat in Australia. The role of the text participant needs to be contextualised in terms of the meaning in the text itself - both the cultural meaning of the word "sheep" and understanding the context and culture to understand the cultural meaning. For example, Australia has a particular colonial history with sheep, relying strongly on sheep as a major agricultural industry. There is a colloquial saying in Australia that the country is "riding on the sheep's back". This was due to the high reliance on the sheep industry as a major export. The song alludes to this as we begin counting sheep and the other species under threat, in part because of the clearing of lands for agricultural production. We listen to the song lyrics as we watch the images:

Sleep, my country, sleep

Sleep, Australia, sleep

As off the cliff the kingdoms leap

Count them as they say goodbye

Count down the little things

The insects and birds

Count down the bigger things

The flocks and the herds

Count down our rivers

Our pastures and trees 

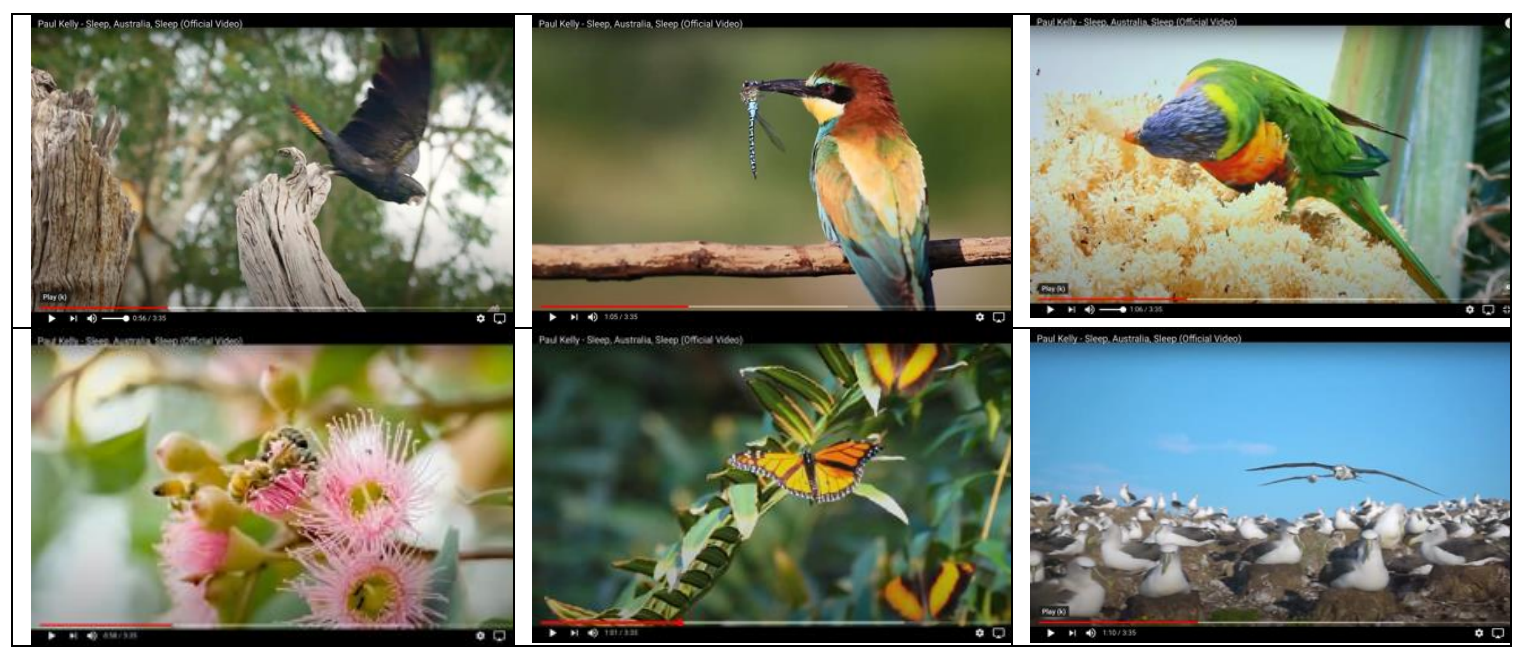

Figure 4. Counting Down the Loss of Insects, Animals and Birds

But there's no need to hurry

Oh, sleep now, don't worry

'Coz it's only a matter of degrees
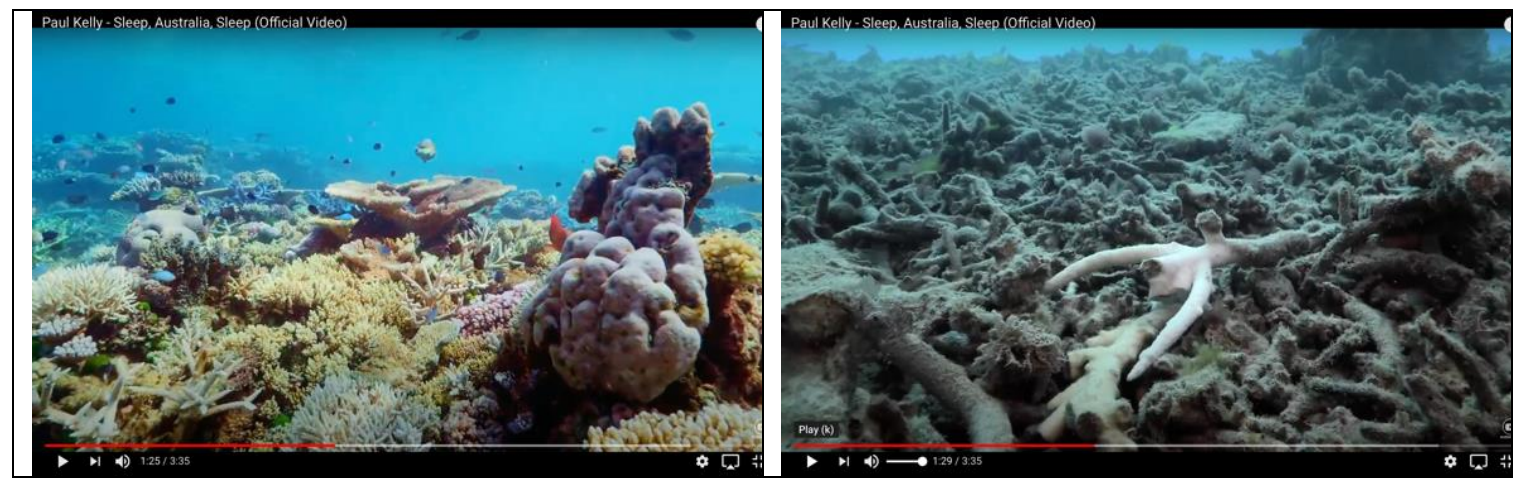

Figure 5. ... a Matter of Degrees

Seeing all of these images together, as Kelly lures his audience into counting the species loss, the text draws upon our memories and knowledge of the situation Australians are in as a nation and as a planet. The cultural context for Australians includes the facts that since colonisation by Europeans in 1788, Australia has lost 100 endemic species, which represents 6-10\% of the world's post-1500 recognised extinctions (Woinarski et al 2019). Kelly's use of sleep as a metaphor in the centre of this loss in the cultural context of Australia, points to our inability to consciously act upon this devastation.

The text user practice explores the purpose of the text and the structures in the text that convey this purpose to the readers. Sleep, Australia, Sleep uses multiple textual genres and forms in its creation. It is a strong persuasive argument, constructed through narrative with the usage of factual documentation. As we have been counting the loss of species, land and reef, the tension builds. When we get to line, "the corpses keep mounting", there 
is a shift in the chord, and multiple aspects of the text construction come together at once to create the meaning. The music changes to the F sharp minor chord, which groans a sense of deep unease and lamentation. Because this is a video, one of the structures in the text is the timing of this moment, and we can see how the text has been structured to punctuate the moment. The pace of the music has become faster and more urgent as we have counted the bodies. When we hear Kelly sing "the corpses keep mounting" we see the images of the iconic Australian birds dead on the beach. One of the effects of the fire was that birds were forced to fly away from land across the sea. Many had enough energy to fly out and did not have enough energy to fly back, and masses of them were washed upon the beach. Many of the white sandy beaches became blackened with charcoal. Birds and charcoal were mixed together and washed on the beaches along the east coast of Australia, the corpses mounting in piles along the beaches (Butt, 2020).
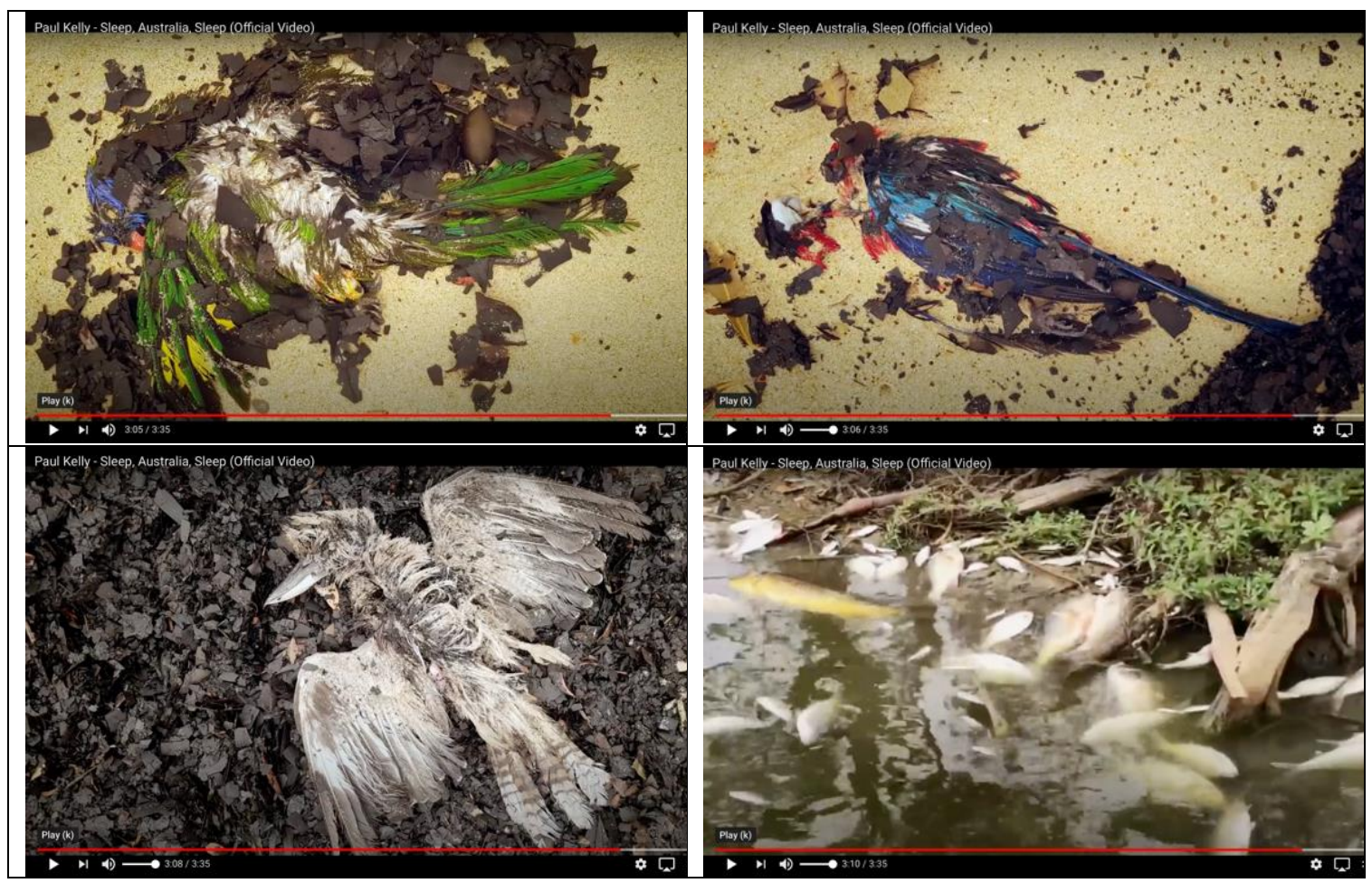

Figure 6. The Corpses Keep Mounting

In engaging with the text analyst practices we consider how the texts 'differentially position readers, and how they use various sociocultural categories, evident in linguistic and visual media, to constrain interpretation and influence the reader to explore the ideologies in the text' (Freebody, 2007, p. 34). By examining the ideology in the text, readers are engaging with the question of whose interests are being served? (Janks, 2010). Sleep, Australia, Sleep identifies the consequences of having humans interact in nonsustainable ways in Australia and beyond. The ideology of holding humans to account for a more sustainable future is evident in the words, the images, the narrative of the text. Our 
analysis shows the ways that the persuasive and narrative forms are utilised to create an emotional response as the reader/viewer/listener is positioned as a witness to the events of the Australian summer of 2020.

We return to the word we began with, "sleep", particularly the idea that that sleeping is marked by an "absence of wakefulness and the loss of consciousness". Although Kelly describes Sleep, Australia, Sleep as a "lament, in the form of a lullaby" evoking these ideas of sleeping, the work is a call to action, to what Greene (1995) called "wideawakeness" and Friere (1974) called "conscientization", rather than designed to put us to sleep. In the video, young people are shown speaking back to the Anthropocene through their positive actions. Youth Action on Climate is a political movement where students have literally walked out of school to address their present and future concerns with respect to the inaction of politics on climate (Mayes \& Holdsworth 2020). In the midst of all the loss and lamentation, Kelly offers us hope through these images of the young people engaging in protests, clean-ups, care for injured animals and work as rangers and firefighters. Freire (1974) identified that critical consciousness without action is limited.
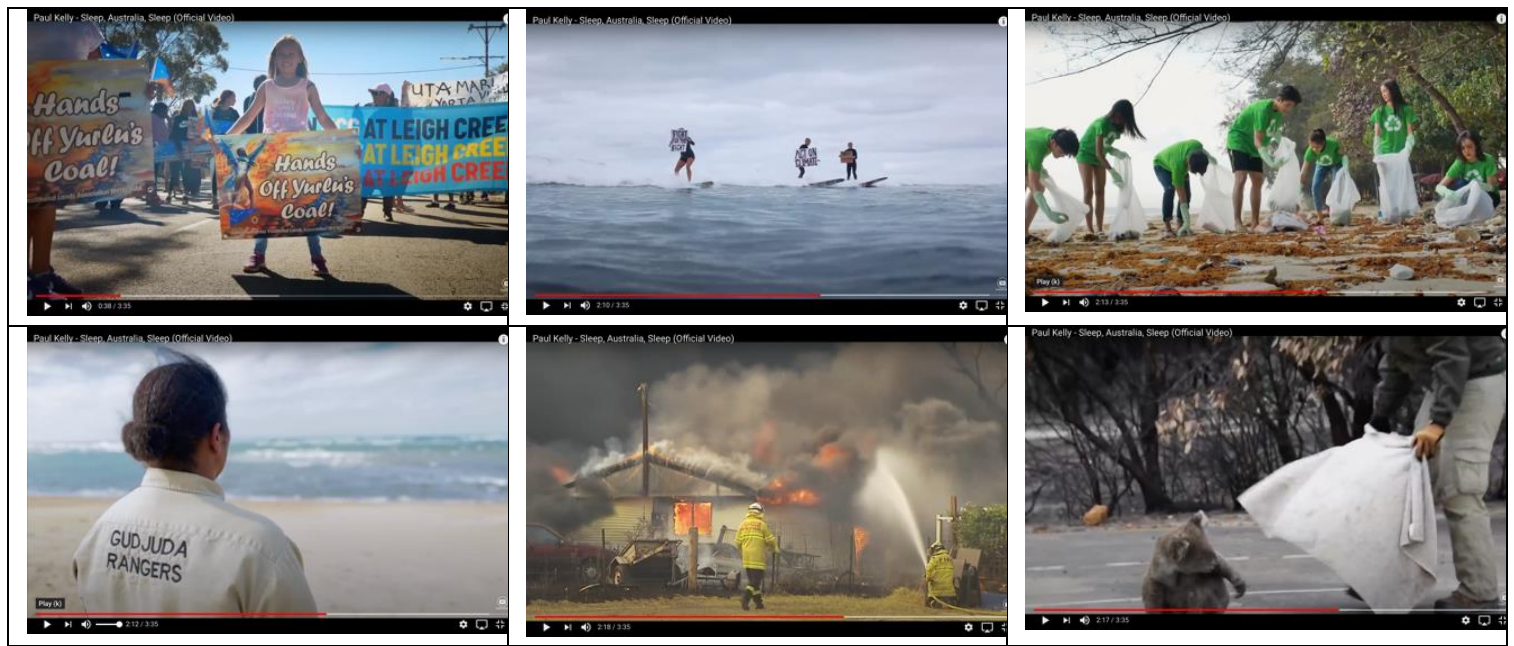

Figure 7. This is Not the End

\section{Conclusions}

Our paper has explored the application of the four practices model to a song video representing a particular moment in time in Australia. Underpinning the model in the inclusive notion of necessary but not sufficient. We explore four important contexts where elements of practice are necessary but not sufficient. Firstly, we identify that the concept of text needs to be inclusive of ways meaning is mediated. For children and young people who no longer differentiate between on and offline (Carrington, 2017), having teachers and a curriculum that is responsive to this textual disposition makes the most of formal learning in school. In Australian language and literacy curriculum, reading and viewing are together-when the word "text" is used educators unproblematically understand it to mean a variety of texts from print to digital, written and multimodal. The openness that Australian literacy educators have, in a large part, can be attributed to the ethos of inclusivity embedded in Four Roles of the Reader Model. 
The concept of necessary but not sufficient has been incorporated into models of pedagogy. If we follow Luke's work, for example, since the development of the model, he has worked with other colleagues to conceive and apply models that are based on a pluralism of pedagogy. The New London Group (1996) conceived pedagogy as four elements of: situated practice, overt instruction, critical framing and transformed practice. When Luke was working for Queensland Education, he supported the implementation of Productive Pedagogies (Newmann and Associates 1996) as the basis of curriculum reform that focused on classrooms having: connectedness, intellectual quality, supportive classroom environments and engagement. Luke brought an inclusive and collaborative approach to teaching practice that was unified around models of pragmatism. This approach to teacher professionalism is one that could unite and diversify practice based on frameworks to negotiate complexity. This pluralistic approach focuses on unifying practice and provides systemic support for long-term professional learning. These plural models of pedagogy also better represent the complexity of children and young people's learning than more narrowly constructed theories of learning.

A third context for the application of necessary but not sufficient lies with teachers of literacy who find themselves stuck between neo-liberal practices of accountability and the ethics of responsibility for the other. Teachers are finding they are working with the tensions of test-based accountability and professional ethics that are largely incompatible (Kostogriz \& Doecke, 2013). Teachers need a pragmatic way of holding competing agendas of literacy together when they don't have the power to change the discourses of accountability but are motivated by an ethic of responsibility. For teachers with limited agency who cannot speak back to standards-based reforms, the ideas of necessary but not sufficient could be a liberating way of approaching literacy pedagogy.

Finally, if we consider the context of literacy learning in the Anthropocene, we might be wise to contextualise human agency as necessary but not sufficient when it comes to understanding responsibility to the more than human other. As Kelly expresses in Sleep, Australia, Sleep, we have been 'lulled into inaction, a critique of the widespread attitude among humans that we are the most important life form on the planet'. In their study of place-based literacies, Comber, Nixon, and Reid (2007) identify that 'the absence of explicit attention towards place and ecological responsibility is a weakness in some forms of critical literacy' (p. 22). Literacy education concerns the complex understandings of literacy: the place of the text and the texts of place, that give rise to a pluralism of human agency and more than human agency. Common world pedagogies are based on students engaging with more than human others as integral to curriculum learning (Taylor, 2017). Our analysis of Sleep, Australia, Sleep using the Four Roles of the reader shows the literary multi-modal strategies Kelly utilises in this text to make it a testament to the importance of the more than human other. Human agency is necessary but not sufficient with respect to moral and political purposes of education.

\section{References}

Butt, C. (2020). It's a sorry sight: dead birds wash up on Malacota beaches. The Age. https://www.theage.com.au/national/victoria/it-s-a-sorry-sight-dead-birds-washup-on-mallacoota-s-beaches-20200107-p53plm.html 
Carrington, V. (2017). How we live now: "I don't think there's such a thing as being offline". Teachers College Record, 119(12), 1-24.

Christie, F., \& Derewianka, B. (2008). School discourse: learning to write across the years of schooling. Continuum.

Clary, D., \& Bannister-Tyrrell, M. (2018). Harnessing research-based practices to critique 'truth'. Literacy Learning: The Middle Years, 26(3), 26-36.

Comber, B., Nixon, H., \& Reid, J.-A. (2007). Environmental communications: Pedagogies of responsibility and place. In B. Comber, H. Nixon, \& J.-A. Reid (Eds.), Literacies in place: teaching environmental communications (pp. 11-23). Primary English Teaching Association.

Fellowes, J., \& Oakley, G. (2019). Language, literacy And early childhood education eBook. Oxford University Press Australia.

Freebody, P. (2007). Education in school: Research perspectives from the past, for the future. Australian Educational Review. http://research.acer.edu.au/aer/1

Freebody, P., \& Luke, A. (1990). Literacies programs: Debates and demands in cultural context. Prospect, 5(3), 7-16.

Freire, P. (1974). Pedagogy of the oppressed (1st ed.). Penguin Books.

Greene, M. (1995). Releasing the imagination : essays on education, the arts, and social change (1st ed.). Jossey-Bass Publishers.

Janks, H. (2010). Literacy and power. Taylor \& Francis Group.

Kostogriz, A., \& Doecke, B. (2013). The ethical practice of teaching: accountability or responsibility? Australian Journal of Language and Literacy, 36(2), 90-98.

Luke, A. (2000). Critical literacy in Australia: A matter of context and standpoint. Journal of Adolescent and Adult Literacy, 43(5), 448-461.

Luke, A., \& Freebody, P. (1999). Map of possible practices: Further notes on the four resources model. Practically Primary, 4(12), 5-8.

Martyn, S. (2020). 'A tipping point': Paul Kelly's new song attacks climate inaction. The Sydney Morning Herald. https://www.smh.com.au/culture/music/a-tipping-pointpaul-kelly-s-new-song-attacks-climate-inaction-20200130-p53w5t.html

Sawyer, W. (2019). Charged with meaning : becoming an English teacher (2nd ed.). Phoenix Education.

Serafini, F. (2012). Expanding the four resources model: reading visual and multi-modal texts. Pedagogies: An International Journal, 7(2), 150-164. https://doi.org/10.1080/1554480X.2012.656347

Taylor, A. (2017). Beyond stewardship: common world pedagogies for the Anthropocene. Environmental Education Research, 23(10), 1448-1461. https://doi.org/10.1080/13504622.2017.1325452

Winch, G., Johnson, R. R., March, P., Ljungdahl, L., \& Holliday, M. (2020). Literacy: reading, writing and children's literature (6th ed.). Oxford University Press.

Woinarski, J. C. Z., Garnett, S. T., Legge, S. M., Murphy, B. P., Braby, M. F., Burbidge, A. A., Coates, D., Fensham, R. J., Silcock, J. L., \& McKenzie, N. L. (2019). Reading the black book: The number, timing, distribution and causes of listed extinctions in Australia. Biological Conservation, 239, 1-14. https://doi.org/10.1016/j.biocon.2019.108261 


\section{Author Biographies}

Joanne O'Mara is an Associate Professor of Langauge and Literature Education and Chair of English teaching method at Deakin University. An experienced secondary English and Drama teacher, she has continued to work with young people and schools through her university research. She particularly values the opportunity to work with students to develop their confidence and self-belief. She considers herself extremely lucky to have the opportunity to work with wonderful colleagues on a series of projects that are valuable. This research includes reading for pleasure, literacies and new textual practices; digital play and games; literacy pedagogies and gratitude and secondary English and drama pedagogy.

Dr. Glenn Auld is a Senior Lecturer in the School of Education at Deakin University. He has published on literacy practices, Indigenous education, literacy teaching through gratitude, out of school literacies and children and young people's engagement with digital texts. He won the Betty Watts Award for research into language resources that uphold the linguistic rights of Ndjebbana speakers. He is currently researching literacy pedagogies for Bad Settlers in projects that realise the political futures and sovereign rights of Indigenous Australians.

Narelle Wood has completed her Bachelor of Science, with Honours, as well as her Graduate Diploma and Masters of Education. Narelle has also worked as a leading teacher as Head of English and Literacy at a high performing girls' school and a lecturer in teacher in the Education Faculty at Monash University and a teaching associate at Deakin University. She is currently working as a Community Projects Coordinator for Parliament of Victoria and is also working on her PhD specifically looking at English teacher accounts of creativity. 


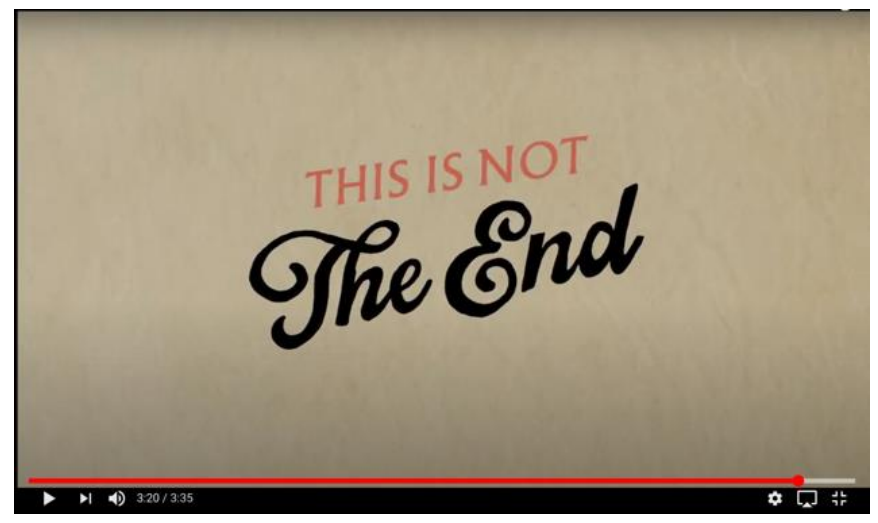

Sleep, Australia, sleep

The night is on the creep

Shut out the noise all around

Sleep, Australia, sleep

And dream of counting sheep

Jumping in fields coloured brown

Who rock the cradle and cry?

Who rock the cradle and cry?

Sleep, Australia, sleep

As off the cliff the kingdoms leap

Count them as they say goodbye

Count down the little things

The insects and birds

Count down the bigger things

The flocks and the herds

Count down our rivers

Our pastures and trees

But there's no need to hurry

Oh, sleep now, don't worry

'Coz it's only a matter of degrees

Fog, Australia, fog

Just like the boiling frog

As we go we won't feel a thing

Who'll rock the cradle and cry?

Who'll rock the cradle and cry?

Sleep, my country, sleep

As off the cliff the kingdoms leap

Count them as they pass on by

Our children might know them 
But their children will not

We won't know 'til it's gone

All the glory we've got

But there are more wonders coming

All new kinds of shows

With acid seas rising

To kiss coastal mountains

And big cyclones pounding

And firestorms devouring

And we'll lose track of counting

As the corpses keep mounting

But hey, that's just the way this old world goes

Sleep, my country, sleep

As we sow so shall we reap

Who'll rock the cradle and cry? 


\section{Appendix B: Questions for Sleep, Australia, Sleep}

1. Look up the word "sleep" in an online dictionary (use one of Cambridge/Oxford/Macquarie/Merriam-Webster). What are the dictionary definitions of sleep? How many of these definitions apply (to both the words and images)? Are there synonyms that would be equivalent to use in place of sleep? If so, how might the new word change the meaning? Who's sleeping? Are there any other words in the song that have multiple meanings?

2. Have a look at the verse 'Fog, Australia, fog'. What are the different meanings of 'fog' represented in the song through both the use of images of types of fog and the word itself? How is this represented in the video clip? What resources did you use to determine the meaning?

3. Scroll through the images used in the video-pick one to "code-break". How is this image shot-Is it from above, below, close-up or far away? How does the way it has been composed change the meaning? (from code-breaking to meaning-making). What colours are in the image? How do the colours influence your understanding? (from code-breaking to meaning-making) How do the images inform/influence your understanding of the text? Did the images clarify the meaning of the song lyrics?

4. For the musically minded:

Stewart Greenhill has provided Ukelele tabs (can also be used on guitar) for the Sleep, My Country, Sleep. http://stewartgreenhill.com/ukulele/SleepAustraliaSleep.html

You can follow through the song playing and see where all of the key changes occur. There is also a map of the chord changes and progressions. Have a listen to the chord change to F\# minor? (The shift occurs on the word "corpses"). What is the impact of the F\# minor?

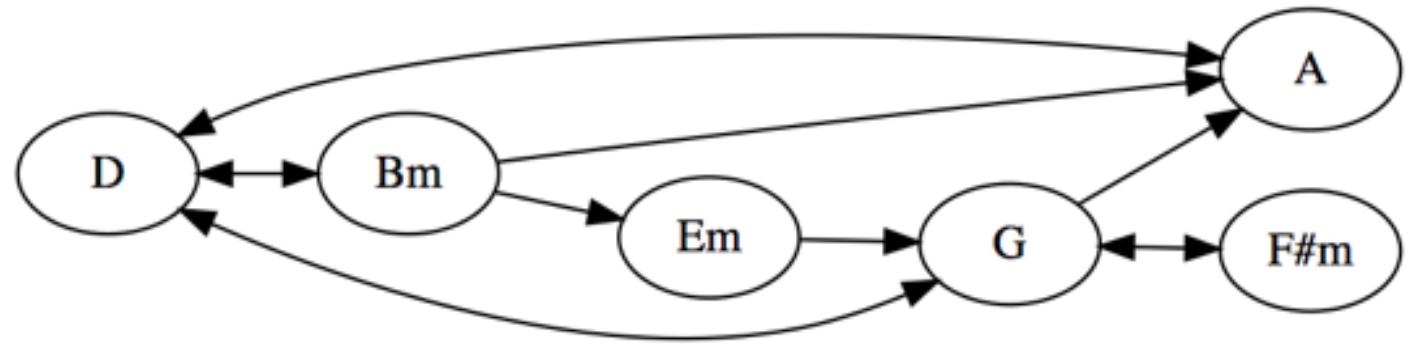

5. How does watching and listening to Sleep, Australia, Sleep make you feel? Why do you think this is the case?

6. In the second half of the song, the words shift from "Sleep, Australia sleep" to Sleep, my country, sleep". Listen to the famous Australian poem, My Country, by Dorothea Mackellar https://www.youtube.com/watch?v=jEHSMQpJDno Further information about the poem is found at: https://www.sl.nsw.gov.au/stories/dorothea-mackellars-my-country Why do you think Paul Kelly has made this direct reference to this iconic Australian poem? 7. What message is Paul Kelly presenting? If you are familiar with Paul Kelly's work, how does this help your understanding of the text? What else might you use to inform reading? 
8. What are the children (who go into the tent) thinking/feeling (they are at the beginning and end of the song)? Do their emotions seem to change through the song?

9. What is the genre of the song/video?

10. Make a list of the different textual forms (such as narrative) that are referenced in this work? (Clue: If you compile an extensive list, there are many!). What persuasive elements does this text contain? Identify persuasive elements in the words, the music, the images? What narrative elements does this text contain? Identify narrative elements in the words, the music, the images?

11. How is this text similar to/different from others you have experienced?

12. What is the purpose of Sleep, Australia, Sleep?

13. Whose interests does Sleep, Australia, Sleep serve? Who benefits? Who does not?

14. What might be the principles and ethics of the composer, and how might they fit into our own views of the world?

15. How is the meaning of Sleep, Australia, Sleep shaped by being composed and released at this moment in time in Australia? Thinking about this text and Mackellar's poem, My Country, how might the meaning of "Country" change over time in Australia?

16. How does the planet benefit from engagement with Sleep, Australia, Sleep? 